\title{
A Vector Voltage Modulator for a Dual Inverter with a Floating Bridge to Operate in Normal and Fault Tolerant Mode
}

\author{
V. Fernão Pires \\ Department of Electrical Engineering \\ Sustain.RD, EST Setúbal, Instituto Politécnico Setúbal \\ INESC-ID Lisboa \\ Setúbal, Portugal \\ vitor.pires@estsetubal.ips.pt
}

Armando Cordeiro

ADEEEA, LCEC

ISEL, Instituto Politécnico de Lisboa

INESC-ID Lisboa

Lisboa, Portugal

armando.cordeiro@isel.ipl.pt

\author{
Daniel Foito \\ Department of Electrical Engineering \\ Sustain.RD, EST Setúbal, Instituto Politécnico Setúbal \\ CTS/UNINOVA \\ Setúbal, Portugal \\ daniel.foito@estsetubal.ips.pt \\ J. Fernando Silva \\ Department of Electrical Engineering \\ IST/University of Lisbon \\ INESC-ID Lisboa \\ Lisboa, Portugal \\ fernando.alves@tecnico.ulisboa.pt
}

\begin{abstract}
The dual inverter multilevel converter is characterized by a simple structure using two well-known threephase bridge inverters supplied by two independent $D C$ sources. However, it can be supplied only by a single $D C$ source if one of the bridges uses just a floating $D C$ capacitor. In this case the control is more complex since it is also required to ensure the capacitor voltage regulation. Besides this, if a fault in one of the switches is also considered, the operation of the converter in fault operation mode becomes even more complex. This paper presents a vector voltage modulator that in addition to track the reference of the output $A C$ voltages, also allows the capacitor voltage regulation of the floating bridge. The capability of this modulator to operate the converter in fault tolerant mode under an inverter open switch will also be analyzed. This analysis will allow to verify that the proposed control and modulation strategy presents inherent fault tolerant capability to open switch fault, since it does not require any fault detection algorithm or change in the control or modulation strategy. The capability and operation of the proposed vector voltage modulator will be verified through several simulation studies
\end{abstract}

Keywords - vector voltage modulator; dual inverter; floating bridge; open switch fault, fault tolerant

\section{INTRODUCTION}

Multilevel inverters are today an important solution for many applications. Indeed, they have been proposed for many applications, such as electric trains, high voltage transmission systems $(H V D C)$, Flexible AC Transmission Systems FACTS, storage systems and renewable sources [1-5]. Initially, there was a first category of developed topologies, that have been designated as Diode Clamped Multilevel Inverter (NPC) [5,6], Flying Capacitors Multilevel Inverter [7,8] and Cascaded Hbridge Multilevel inverter $[9,10]$. These topologies have been applied to an important number of applications.
With the purpose to reduce the number of power semiconductors, introduce modularity or increase reliability, many new types of multilevel inverters have been proposed. One group of multilevel inverters that have been proposed and studied is the one associated to the modular topologies. These topologies use several well-known two-level voltage source inverters. One of these topologies is designated modular multilevel converter $(M M C)$. The classical solution of this topology is based in the half-bridge inverter [11], but the MMC have also been used with the classical two level H-bridges [12]. However, for electrical drives this topology requires extra inductors and an important number of $D C$ capacitors. Structures with classical two-level H-bridge but different from the $M M C$ configurations were also proposed [13]. Other type of modular topologies that have been proposed uses classical two-level inverters but with four legs [14-17]. Multilevel topologies based in hybrid configurations employing single and three-phase two-level inverters were also proposed $[18,19]$. Another category of modular multilevel inverters with twolevel inverters uses only three-phase converters [20,21]. From these, the ones that have received more attention are the dual three-phase H-bridge voltage source multilevel inverters. Among the several topologies the designated dual inverter is the most studied [22-24]. This topology consists into two $\mathrm{H}$ bridges voltage source inverters supplied by two independent voltage source inverters. Nevertheless, to avoid the usage of two floating DC power supplies, it was also proposed a topology in which a floating DC capacitor is used in one threephase-bridge $[25,26]$. However, its control is more complex since it is required to ensure the regulation of the capacitor voltage of the floating bridge.

In this paper a vector voltage modulator for the dual inverter with a floating capacitor bridge will be presented hereafter. Besides their capability to track the $A C$ voltage 
references this modulator will also ensure the voltage regulation of the capacitor associated to the floating bridge. Moreover, the capability to operate this converter in fault tolerant mode will be analyzed. Tests of this multilevel inverter with the proposed vector voltage modulator will also be presented.

\section{DUAL INVERTER WITH A FLOATING BRIDGE}

The multilevel dual inverter includes two H-bridge voltage source inverters supplied by two $D C$ voltage sources. However, it is possible to avoid the second $D C$ voltage source using a floating bridge, in which in the $D C$ side of that bridge is replaced by a DC capacitor, as shown in Fig. 1.

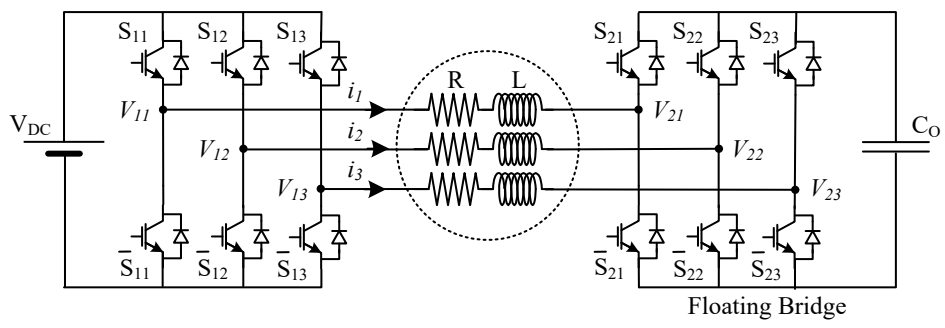

Fig. 1. Topology of the dual inverter with a floating bridge

The dual inverter with the floating capacitor bridge can be modeled considering that the power semiconductors are ideal and associated to a variable $\gamma$ that will be 1 or 0 respectively according to the $O N$ or $O F F$ state of the semiconductors. In agreement with this assumption, the output $A C$ voltages of the multilevel inverter can be written by the following expression:

$\left[\begin{array}{l}V_{o 1} \\ V_{o 2} \\ V_{o 3}\end{array}\right]=\frac{1}{3}\left[\begin{array}{ccc}2 & -1 & -1 \\ -1 & 2 & -1 \\ -1 & -1 & 2\end{array}\right]\left[\begin{array}{l}V_{11} \\ V_{12} \\ V_{13}\end{array}\right]-\frac{1}{3}\left[\begin{array}{ccc}2 & -1 & -1 \\ -1 & 2 & -1 \\ -1 & -1 & 2\end{array}\right]\left[\begin{array}{l}V_{21} \\ V_{22} \\ V_{23}\end{array}\right]$

where

$$
\left\{\begin{array}{l}
V_{1 j}=\gamma_{1 j} V_{D C} \\
V_{2 j}=\gamma_{2 j} V_{C_{0}}
\end{array}\right.
$$

The previous three-phase $A C$ voltages can be converted into a two phase orthogonal system through the application of the Clark-Concordia transformation. In this way, these voltages can also be written by the following new expression:

$$
\begin{aligned}
{\left[\begin{array}{l}
V_{o \alpha} \\
V_{o \beta}
\end{array}\right]=} & {\left[\begin{array}{rrr}
\sqrt{\frac{2}{3}} & -\frac{1}{\sqrt{6}} & -\frac{1}{\sqrt{6}} \\
0 & \frac{1}{\sqrt{2}} & -\frac{1}{\sqrt{2}}
\end{array}\right]\left[\begin{array}{l}
V_{11} \\
V_{12} \\
V_{13}
\end{array}\right]-} \\
& {\left[\begin{array}{ccc}
\sqrt{\frac{2}{3}} & -\frac{1}{\sqrt{6}} & -\frac{1}{\sqrt{6}} \\
0 & \frac{1}{\sqrt{2}} & -\frac{1}{\sqrt{2}}
\end{array}\right]\left[\begin{array}{l}
V_{21} \\
V_{22} \\
V_{23}
\end{array}\right] }
\end{aligned}
$$

Analyzing the previous expression, considering all combinations of switches and assuming that the voltages of the $D C$ source and capacitor are equal, it will be possible to see that in the alfa-beta reference plane 19 distinct vectors are obtained. However, if these voltages are different then the number of voltage vectors is increased. For example, considering that the voltage of the capacitor is half of the $D C$ source, then 37 distinct vectors are obtained, as presented in Fig. 2. However, since the possible combinations of switches are higher (64), a higher number of voltage vectors also exist, although many of them are redundant. These redundant vectors are very important in this topology since they are used to ensure the voltage regulation of in the capacitor connected to the floating inverter, so that $V_{C o}=V_{D C} / 2$.

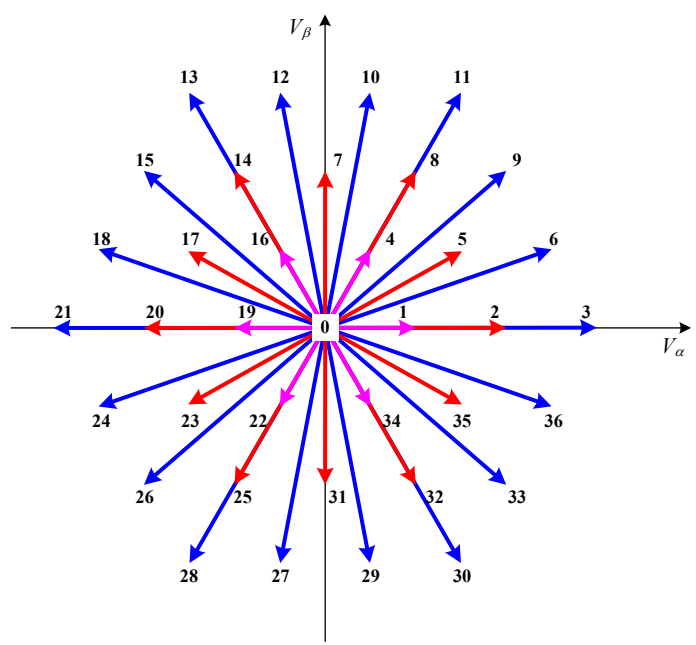

Fig. 2. Voltage vectors in the alfa-beta plane considering that the voltage of of capacitor is half of the DC source

\section{CONTRol of The DuAl INVERTER With A FlOATING CAPACITOR BRIDGE}

With the purpose to ensure that the converter is able to control their $A C$ voltages in a fast and robust way, it is proposed the use of a voltage sliding mode controller together with a vector voltage modulator. From (3) the strong relative degree of the AC voltages is zero [27]. This means the AC voltages are not state quantities. Furthermore, AC voltages being staircase waveforms cannot track sinusoidal references. Therefore, an auxiliary state variable is created using the AC voltages average value in a switching period. Moreover, the sliding surfaces will have to consider the switching period error averages expressed in (4). Thus, the development of the controller is achieved considering the average value of the error between the $A C$ voltages $V_{0 \alpha, \beta}$ in the alfa-beta coordinates and their references $V_{0 \alpha, \beta \text { ref }}$ during a switching period $T$ (4).

$$
\frac{1}{T} \int_{0}^{T} V_{0 \alpha, \beta r e f} d t-\frac{1}{T} \int_{0}^{T} V_{0 \alpha, \beta} d t=e_{V 0 \alpha, \beta}=0
$$

From (4), the two sliding surfaces of the controller will be defined by: 


$$
\left\{\begin{array}{l}
S\left(e_{\alpha}, t\right)=\frac{k_{\alpha}}{T} \int_{0}^{T}\left(V_{0 \alpha r e f}-V_{0 \alpha}\right) d t=0 \\
S\left(e_{\beta}, t\right)=\frac{k_{\beta}}{T} \int_{0}^{T}\left(V_{0 \beta r e f}-V_{0 \beta}\right) d t=0
\end{array}\right.
$$

Where $k_{\alpha} \quad k_{\beta}$ are positive constants that impose the switching frequency and ensure the control response speed in accordance with the conditions defined by the sliding surfaces described by (5). The sliding mode stability condition $S\left(e_{\alpha \beta}, t\right) \dot{S}\left(e_{\alpha \beta}, t\right)<0$ [27-29] is ensured by choosing a vector so that if $S\left(e_{\alpha \beta}, t\right)>0$, then the chosen vector will cause $\dot{S}\left(e_{\alpha \beta}, t\right)<0$. Otherwise, if $S\left(e_{\alpha \beta}, t\right)<0$, then the chosen vector must cause $\dot{S}\left(e_{\alpha \beta}, t\right)>0$. This will be achieved through a voltage vector modulator. Taking into account that there are two sliding surfaces, the modulator will have two inputs. Between there inputs and the sliding surfaces there will be two hysteretic comparators with five levels each. The number of levels was defined taking into consideration the amplitude of the voltage vectors according alfa and beta axis. In this way, the implementation of the vector voltage modulator can be realized by a look up table, as shown in Table I.

TABLE I. LOOKUP TABLE USED FOR THE VECTOR VOLTAGE MODULATOR

\begin{tabular}{|c|c|c|c|c|c|}
\hline $\boldsymbol{\lambda}_{\boldsymbol{\beta} \boldsymbol{\beta}} \backslash \boldsymbol{\lambda}_{\boldsymbol{\alpha} \boldsymbol{\alpha}}$ & $\mathbf{- 2}$ & $\mathbf{- 1}$ & $\mathbf{0}$ & $\mathbf{1}$ & $\mathbf{2}$ \\
\hline $\mathbf{- 2}$ & 26,28 & 27,25 & 31 & 29,32 & 30,33 \\
\hline $\mathbf{- 1}$ & 23,24 & 22 & 31 & 34 & 35,36 \\
\hline $\mathbf{0}$ & 20,21 & 19 & 0 & 1 & 2,3 \\
\hline $\mathbf{1}$ & 17,18 & 16 & 7 & 4 & 5,6 \\
\hline $\mathbf{2}$ & 13,15 & 12,14 & 7 & 8,10 & 9,11 \\
\hline
\end{tabular}

The regulation to the value $V_{D C} / 2$ of the capacitor voltage associated to the floating bridge is ensured by the redundant voltage vectors. An example can be seen for the vector 4 . Associated to this vector there are two more redundant vectors (the 3 vectors can be designated from $4 \mathrm{~A}$ to $4 \mathrm{C}$ ). Each vector presents different semiconductor switching combinations, although the amplitude in accordance with the alfa and beta axis is the same as shown in Table II. The choice of the redundant vector must also take into consideration the direction of the $A C$ currents. For this, eight sectors are considered as shown in Fig. 3.

TABLE II. REDUNDANT VOLTAGE VECTORS ASSOCIATED TO VECTOR 4

\begin{tabular}{|c|c|c|c|c|c|c|c|c|}
\hline Vector & $\mathbf{S}_{\mathbf{1 1}}$ & $\mathbf{S}_{\mathbf{1 2}}$ & $\mathbf{S}_{\mathbf{1 3}}$ & $\mathbf{S}_{\mathbf{2 1}}$ & $\mathbf{S}_{\mathbf{2 2}}$ & $\mathbf{S}_{\mathbf{2 3}}$ & $\boldsymbol{V}_{\boldsymbol{o} \boldsymbol{\alpha}}$ & $\boldsymbol{V}_{\boldsymbol{o} \boldsymbol{\beta}}$ \\
\hline $4 \mathrm{~A}$ & 0 & 0 & 0 & 0 & 0 & 1 & $0,20 \mathrm{~V}_{\mathrm{DC}}$ & $0,35 \mathrm{~V}_{\mathrm{DC}}$ \\
\hline $4 \mathrm{~B}$ & 1 & 1 & 0 & 1 & 1 & 1 & $0,20 \mathrm{~V}_{\mathrm{DC}}$ & $0,35 \mathrm{~V}_{\mathrm{DC}}$ \\
\hline $4 \mathrm{C}$ & 1 & 1 & 1 & 0 & 0 & 1 & $0,20 \mathrm{~V}_{\mathrm{DC}}$ & $0,35 \mathrm{~V}_{\mathrm{DC}}$ \\
\hline
\end{tabular}

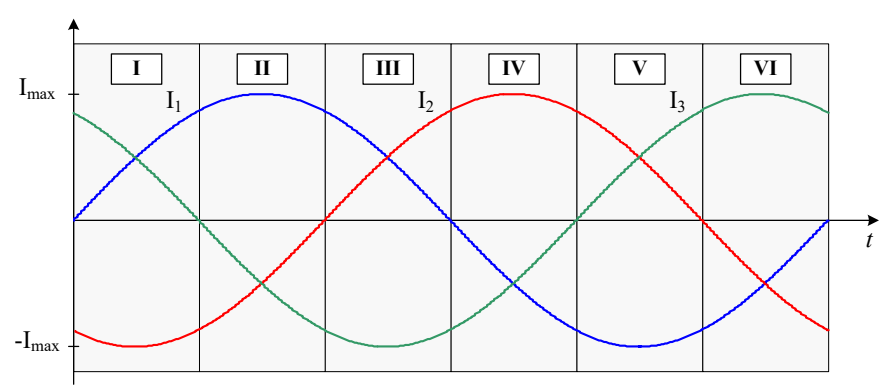

Fig. 3. $A C$ currents and correspondet sectors

Another aspect is the operation of the system when there is an open switch fault. In this situation automatically several voltage vectors are not available. For example, let's consider that there is a fault in the switch $S_{11}$. In this case the voltage vectors $2,3,5,6,8,9,10,11,29,30,32,33,35$ and 36 are not available anymore (Fig. 4). However, if for example the vector 6 is chosen, in reality, due to the fault the vector that will be applied will be vector 4 (the vector that has the same switching combination except the $S_{11}$ that instead be 1 will be 0 ). However, this vector still maintains in the same quadrant of the chosen vector, although with less amplitude. So, if the required voltage reference is not at their maximum value, then the system will be able to operate in fault tolerant mode. It should be noticed that this change is automatic, requiring no fault detection algorithm. So, the proposed system inherently provides fault tolerance capability, despite not operating at its maximum voltage.

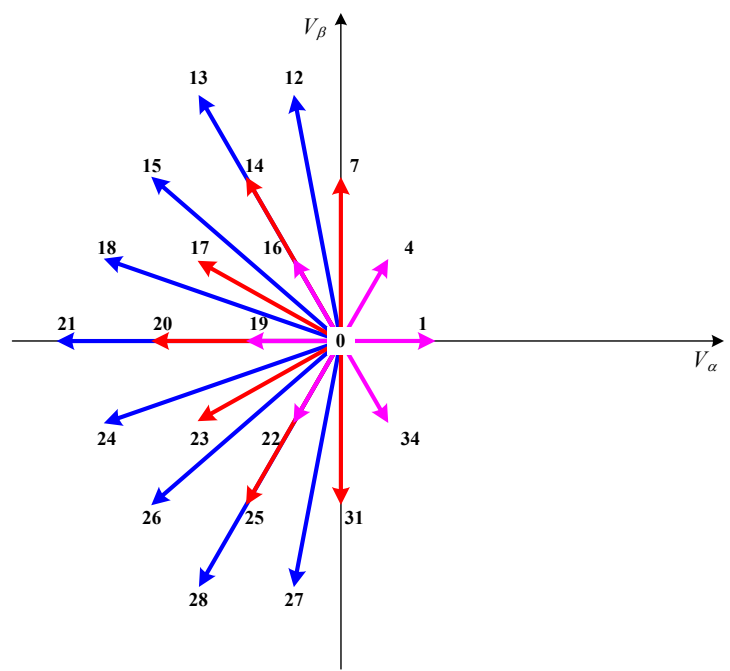

Fig. 4. Voltage vectors in the alfa-beta plane considering an open switch fault $\left(\mathrm{S}_{11}\right)$

The proposed full control strategy for the dual inverter with the floating capacitor can be seen in Fig. 5. As shown by this figure, for the space vector modulator there are seven inputs since it depends of the sliding mode controller, capacitor voltage and $A C$ current sectors. 


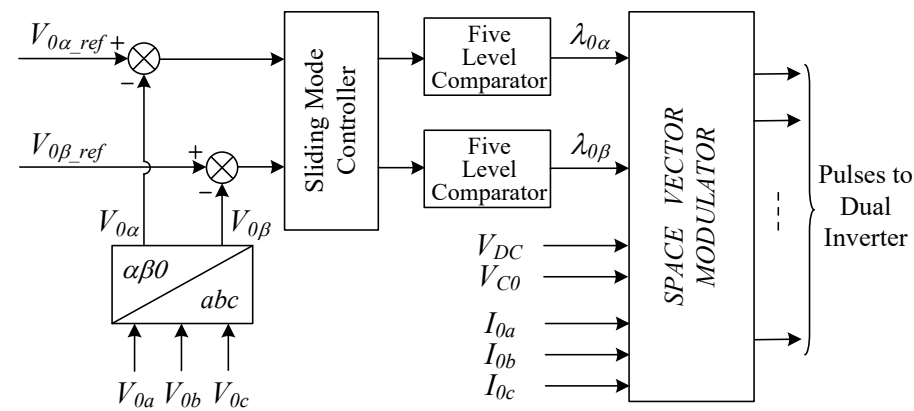

Fig. 5. Full control system adopted for the dual inverter with the floating capacitor

\section{Simulation Tests}

Some simulation tests were performed using the Matlab/Simulink program. A $600 \mathrm{~V}$ DC voltage source was adopted and for the floating capacitor voltage was regulated to $300 \mathrm{~V}$. Through Fig. 6 it is possible to see the time behavior of the output voltage of the dual inverter and ac currents. From this figure it is possible to confirm the multilevel operation of the dual inverter since the ac voltage of this converter presents 9 voltage levels. From Fig. 6 b) it is possible to confirm that the ac currents of the converter currents are almost sinusoidal. The capability of the controller and modulator to regulate the voltage of the floating capacitor can also be seen in Fig. $6 \mathrm{c}$ ).

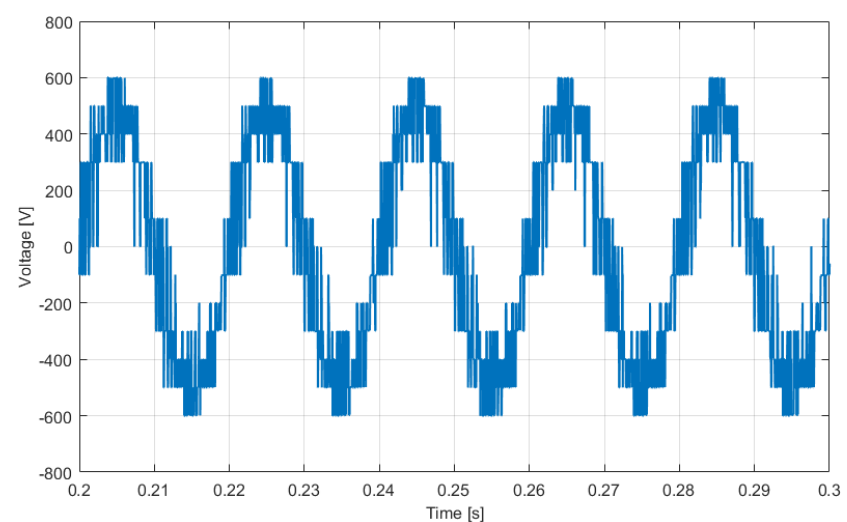

a)

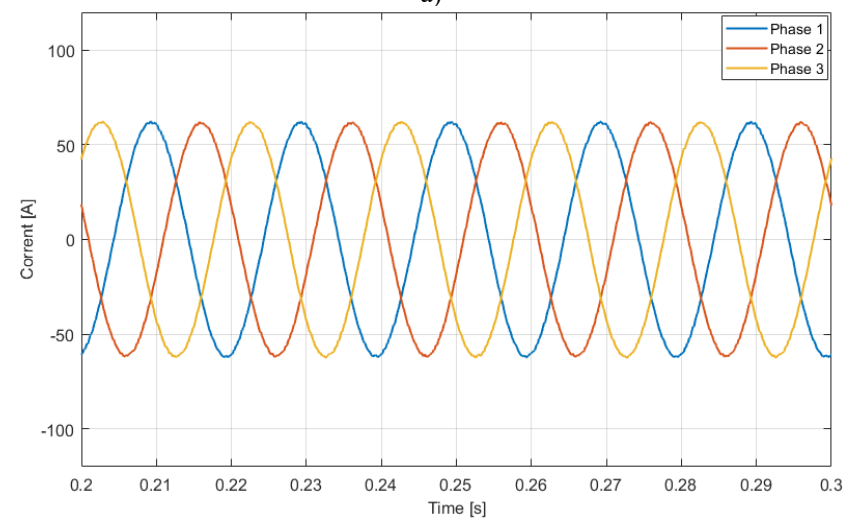

b)

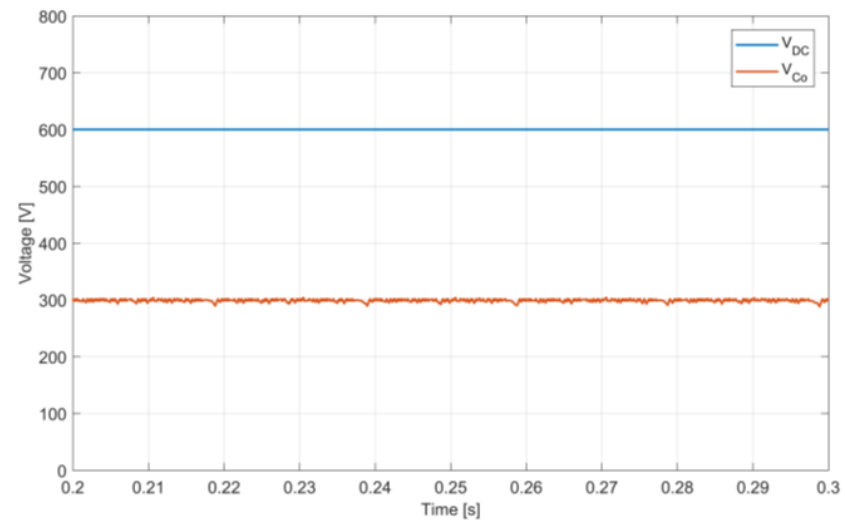

c)

Fig. 6. Waveforms of the a) $A C$ output voltage, b) $A C$ output currents and c) of the $D C$ and floating capacitor voltages in heltly condition

The operation of the converter under an open switch fault was also tested. The results of a test in which the switch $S_{2 I}$ (associated to the floating bridge) is in open fault can be seen in Figure 7. Through this figure it is possible to see that even in the situation of a fault in the floating bridge the AC currents still maintain with a low THD (although somewhat increased compared to the healthy condition value). In this situation the operation of the converter is practically not affected. The waveform of the voltage in the floating capacitor is shown in Fig. 7 c). From this figure is possible to see that higher ripple appears in this waveform. However, the voltage regulation is only slightly affected.

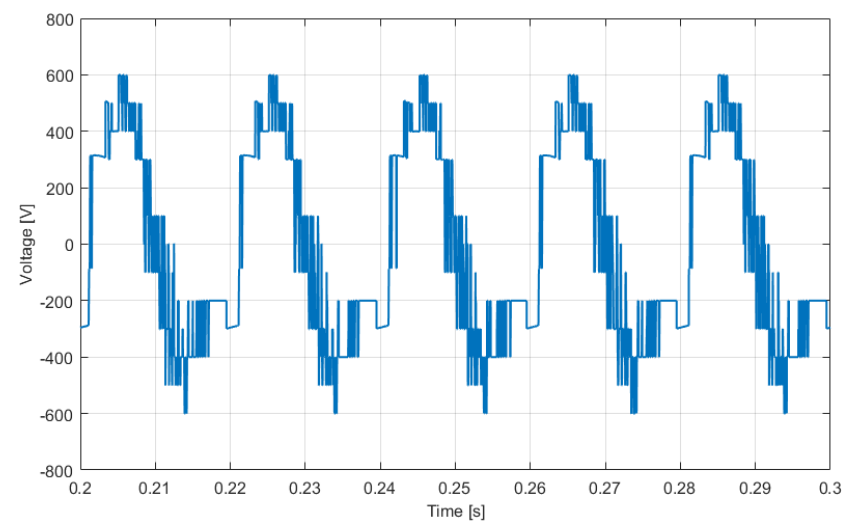

a)

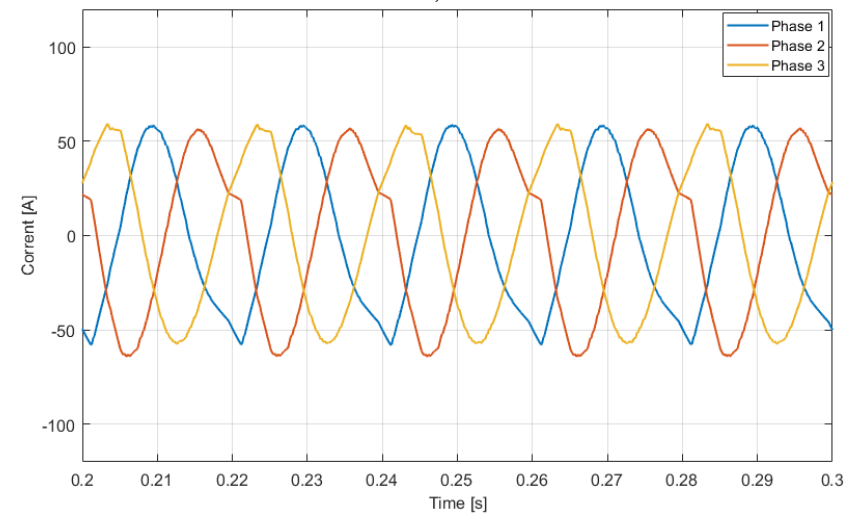

b) 


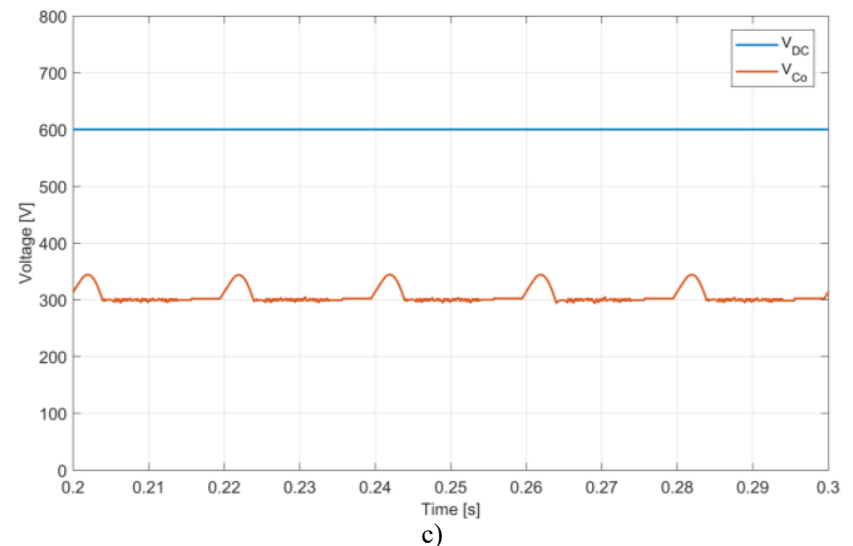

Fig. 7. Waveforms of the a) $A C$ output voltage, b) $A C$ output currents and c) of the $D C$ and floating capacitor voltages for an open fault in switch $S_{21}$.

A new test with the converter under an open switch fault, but in this case for the switch $S_{12}$ that is associated with the other inverter (bridge connected to the $D C$ voltage source) was also performed. The obtained results of this open fault can be seen in Figure 8. Through this figure it is possible to see that in this case the $A C$ currents are much more affected, although the effect cannot be considered catastrophic. Regarding the capacitor voltage is also possible to verify that it is much more affected. Indeed, in this case the ripple is high (around 33\%) and specially associated to under voltages that will affect the $A C$ currents.

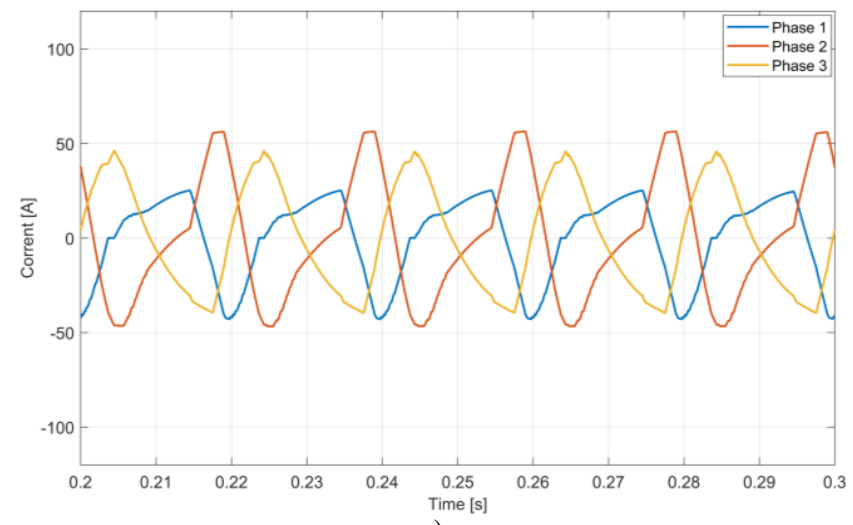

a)

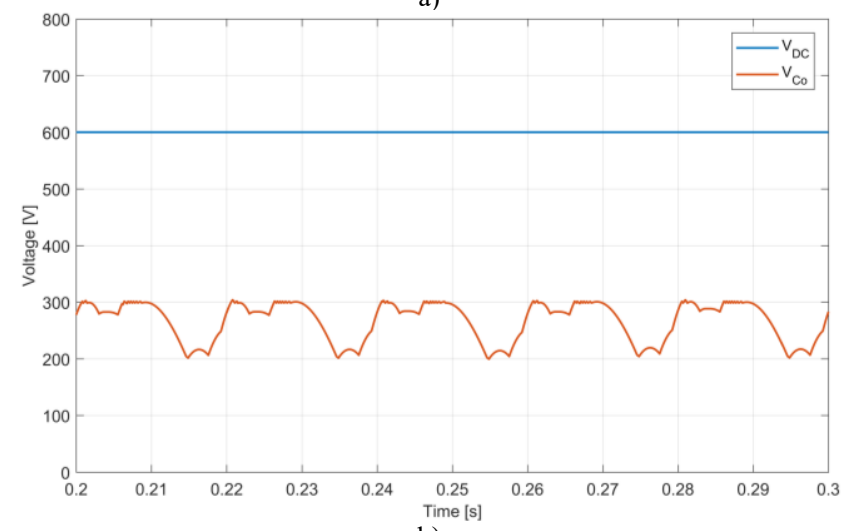

b)

Fig. 8. Waveforms of the a) $A C$ output currents and b) of the $D C$ and floating capacitor voltages for an open fault in switch $S_{12}$.
An identical test in which the converter under an open switch fault for the switch $S_{12}$ (that is associated to the bridge connected to the $D C$ voltage source) but for a reduced output $A C$ voltage (reduced power) was performed. Fig. 9 presents the obtained results for the $A C$ output currents and $D C$ and floating capacitor voltages. From this figure it is possible to conclude that with the reduction of the $A C$ voltage the currents are practically not affected. The same happens for the capacitor voltage, since compared with the previous test the ripple presents an important reduction.

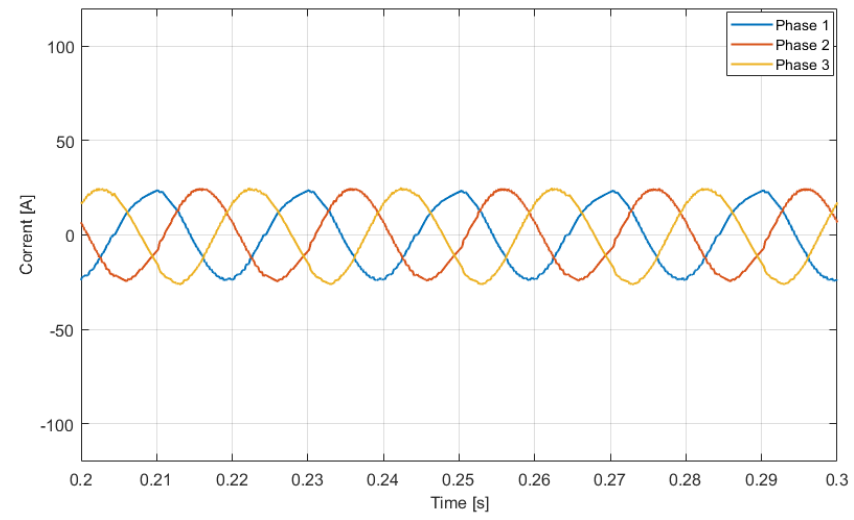

a)

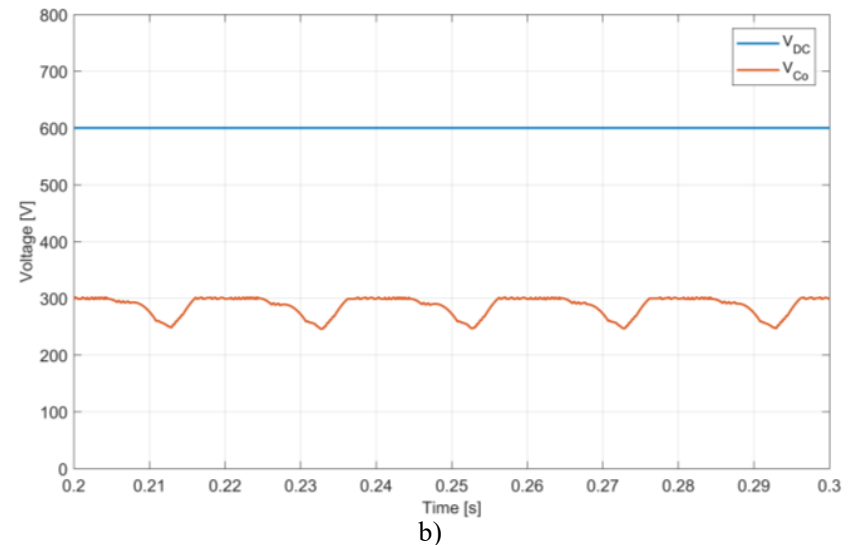

Fig. 9. Waveforms of the a) $A C$ output currents and b) of the $D C$ and floating capacitor voltages for an open fault in switch $S_{12}$.

An important factor that should be highlighted is that all the tests were realized without changing the control or modulation strategy. Thus, this indicates that the system shows fault tolerance capability for open switch fault with some output power limitations without requiring any fault detection algorithm or change in the control or modulation strategy.

\section{CONCLUSIONS}

This work presented a sliding mode vector control system for a voltage modulator of a dual inverter with a floating capacitor bridge. The controller was designed taking into consideration a sliding mode approach and sliding mode stablity. Associated to this controller, a vector voltage modulator was obtained. The design of the modulator took into consideration the regulation of the floating capacitor voltage. Another aspect that was studied was the capability of the system to operate under open switch faults. From this study it 
was possible to verify that the proposed control and modulation strategy presents inherent fault tolerant capability to open switch faults, as it does not require any fault detection algorithm or any change in the control or modulation strategy. With the purpose to verify the capability and characteristics of the proposed control system, several simulations were carried out. The obtained results showed the capability to control the converter, was well as, to maintain their operation with a fault in one of the switches.

\section{ACKNOWLEDGMENT}

This work was supported by national funds through FCT Fundação para a Ciência e a Tecnologia with reference UIDB/50021/2020 and UIDB/00066/2020.

\section{REFERENCES}

[1] I. Colak, E. Kabalci, R. Bayindir, "Review of multilevel voltage source inverter topologies and control schemes", Energy Conversion and Management, vol. 52, Issue 2, pp. 1114-1128, February 2011.

[2] A. Nami, J. Liang, F. Dijkhuizen and G. D. Demetriades, "Modular multilevel converters for HVDC applications: Review on converter cells and functionalities", IEEE Transactions on Power Electronics, vol. 30, no. 1, pp. 18-36, January 2015.

[3] V. Rallabandi, O. M. Akeyo and D. M. Ionel, "Modeling of a multimegawatt grid connected PV system with integrated batteries," IEEE International Conference on Renewable Energy Research and Applications, pp. 1146-1151, November 2016.

[4] P. Omer, J. Kumar and B. S. Surjan, "A Review on Reduced Switch Count Multilevel Inverter Topologies," in IEEE Access, vol. 8, pp. 22281-22302, January 2020.

[5] H. Abu Bakar Siddique, A. R. Lakshminarasimhan, C. I. Odeh and R. W. De Doncker, "Comparison of modular multilevel and neutral-pointclamped converters for medium-voltage grid-connected applications," IEEE International Conference on Renewable Energy Research and Applications, pp. 297-304, November 2016.

[6] G. Finamor, M. D. Pai, H. Pinheiro and L. Schuch, "Transformerless interleaving multilevel NPC inverter for photovoltaic systems," 2015 IEEE 13th Brazilian Power Electronics Conference and 1st Southern Power Electronics Conference, pp. 1-6, Nov.-Dec. 2015.

[7] A. Shukla, A. Ghosh and A. Joshi, "Improved Multilevel Hysteresis Current Regulation and Capacitor Voltage Balancing Schemes for Flying Capacitor Multilevel Inverter," IEEE Transactions on Power Electronics, vol. 23, no. 2, pp. 518-529, March 2008.

[8] A. M. Y. M. Ghias, J. Pou, G. J. Capella, V. G. Agelidis, R. P. Aguilera, T. Meynard, "Single-Carrier Phase-Disposition PWM Implementation for Multilevel Flying Capacitor Converters," IEEE Transactions on Power Electronics, vol. 30, no. 10, pp. 5376-5380, October 2015.

[9] L. Comparatore, A. Renault, J. Pacher, J. Rodas and R. Gregor, "Finite Control Set Model Predictive Control Strategies for a Three-Phase Seven-level Cascade H-Bridge DSTATCOM," International Conference on Renewable Energy Research and Applications, pp. 779-784, October 2018.

[10] B. Xiao, L. Hang, J. Mei, C. Riley, L. M. Tolbert and B. Ozpineci, "Modular Cascaded H-Bridge Multilevel PV Inverter With Distributed MPPT for Grid-Connected Applications," IEEE Transactions on Industry Applications, vol. 51, no. 2, pp. 1722-1731, March-April 2015.

[11] M. S. Diab, A. M. Massoud, S. Ahmed and B. W. Williams, "A Dual Modular Multilevel Converter With High-Frequency Magnetic Links Between Submodules for MV Open-End Stator Winding Machine Drives," IEEE Transactions on Power Electronics, vol. 33, no. 6, pp. 5142-5159, June 2018.

[12] W. Yang, Q. Song, S. Xu, H. Rao and W. Liu, "An MMC Topology Based on Unidirectional Current H-Bridge Submodule With Active
Circulating Current Injection," IEEE Transactions on Power Electronics, vol. 33, no. 5, pp. 3870-3883, May 2018.

[13] S. K. Yadav, N. Mishra, B. Singh, S. Padmanaban, F. Blaabjerg, "Modified SPWM technique for improved harmonic performance of single PV array fed grid-tied five-level converter", IET Power Electronics, vol. 13, Issue 9, pp. 4498-4506, December 2020.

[14] V. Pires, A. Cordeiro, D. Foito and F. Silva, "A Multilevel Converter Topology for a STATCOM System Based on Four-Leg Two-Level Inverters and Cascaded Scott Transformers," in IEEE Transactions on Power Delivery, doi: 10.1109/TPWRD.2021.3086399.

[15] F-S. Kang, S. E. Cho, S-J. Park, C-U. Kim, T. Ise, "A new control scheme of a cascaded transformer type multilevel PWM inverter for a residential photovoltaic power conditioning system," Solar Energy, 2005, vol. 78, Issue 6, pp. 727-738, June 2005.

[16] V. F. Pires, D. Foito, A. Cordeiro, "PV Power Conditioning System Using A Three-Phase Multilevel Pulse Width Modulation Inverter Employing Cascaded Scott Transformers", IET Power Electronics, vol. 12, Issue 1, pp. 102-111, January 2019

[17] L. Zhou, Q. Fu, X. Li and C. Liu, "A novel photovoltaic grid-connected power conditioner employing hybrid multilevel inverter," International Conference on Sustainable Power Generation and Supply, pp. 1-7, April 2009.

[18] V. F. Pires, J. Monteiro, J. F. Silva, "A Grid-Connected PV Multilevel Cascaded Inverter System Based on Single and Three-Phase Two-Level Inverters", International Conference on Renewable Energy Research and Applications, pp. 1-6, November 2019.

[19] T. Qanbari and B. Tousi, "Single-Source Three-Phase Multilevel Inverter Assembled by Three-Phase Two-Level Inverter and Two Single-Phase Cascaded H-Bridge Inverters," in IEEE Transactions on Power Electronics, vol. 36, no. 5, pp. 5204-5212, May 2021.

[20] V. F. Pires, D. Foito and J. F. Silva, "Fault-Tolerant Multilevel Topology Based on Three-Phase H-Bridge Inverters for Open-End Winding Induction Motor Drives," IEEE Transactions on Energy Conversion, vol. 32, no. 3, pp. 895-902, September 2017.

[21] D. Foito, V. Pires, A. Cordeiro, J. Silva, "Sliding Mode Vector Control of Grid-Connected PV Multilevel Systems Based on Triple Three-Phase Two-Level Inverters", International Conference on Renewable Energy Research and Applications, pp. 399-404, September 2020.

[22] D. Casadei, G. Grandi, A. Lega and C. Rossi, "Multilevel Operation and Input Power Balancing for a Dual Two-Level Inverter with Insulated DC Sources," IEEE Transactions on Industry Applications, vol. 44, no. 6, pp. 1815-1824, Nov.-dec. 2008.

[23] B. Wang, X. Zhang, C. Song, R. Cao, "Research on the Filters for DualInverter Fed Open-End Winding Transformer Topology in Photovoltaic Grid-Tied Applications", Energies, Vol 12, Issue 12, pp. 1-21, 2019.

[24] R. Menon, S. Williamson, N. Azeez, A. Kadam, "A Fault Tolerant Modulation Strategy for Dual Inverter Traction Drives," IEEE Energy Conversion Congress and Exposition, pp. 5856-5861, Sep-Oct. 2019.

[25] S. Chowdhury, P. W. Wheeler, C. Gerada and C. Patel, "Model Predictive Control for a Dual-Active Bridge Inverter With a Floating Bridge," IEEE Transactions on Industrial Electronics, vol. 63, no. 9, pp. 5558-5568, September 2016.

[26] V. F. Pires, A. Cordeiro and J. F. Silva, "Dual Inverter with a Floating Bridge Controlled by a Vectorial Voltage Modulator," 16th Biennial Baltic Electronics Conference, 2018, pp. 1-4, October 2018.

[27] J. F. Silva, S. F. Pinto, Linear and nonlinear control of switching power converters, in Power Electronics Handbook, ed. M. Rashid, pp 11411220, 2018.

[28] J. F. Silva, V. F. Pires, S. F. Pinto, J. D. Barros, "Advanced Control Methods for Power Electronics Systems", Mathematics and Computers in Simulation, Elsevier, vol. 63, Issue 3-5, pp. 281-295, November 2003

[29] J. Y. Hung, W. Gao and J. C. Hung, "Variable structure control: a survey," IEEE Transactions on Industrial Electronics, vol. 40, no. 1, pp. 2-22, February 1993. 